\title{
Analysis and evaluation of the renewability of the deep groundwater in the Huaihe River Basin, China
}

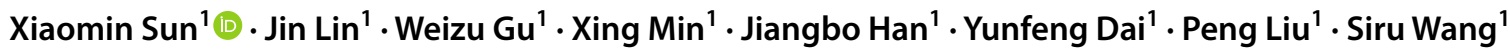

Received: 1 September 2019 / Accepted: 22 December 2020 / Published online: 29 January 2021

(c) The Author(s) 2021

\begin{abstract}
Groundwater is the major source for resident drinking, industrial development, and agricultural irrigation in the Huai River Basin (HRB). With the development of industry and agriculture, exploitation of the deep groundwater increases dramatically in the HRB in recent years. Therefore, analysis and evaluation the renewability of the deep groundwater in the HRB is critical. In our study, a total of 390 groundwater samples were collected along four profiles in 35 cities and counties within the HRB to obtain their hydrochemical characteristics and isotopic data. Based on the isotopic data of these samples, three deep groundwater subsystems: the Shaying River System, the Guohe River System, and the Ancient Yellow River System were identified. The further comparison indicates that the deep and shallow groundwater systems of Guohe River System and Shaying River System have good differentiation. While, the connection of deep and shallow aquifer of Ancient Yellow River System is strong. According to the calculation results based on the combination of stable isotopes and water chemistry, the renewable ability of deep groundwater of Ancient Yellow River, Shaying river, and Guo river are 36\%, 22\%, and 12\%, respectively, which implies faster renewal rate and greater exploitation potential.
\end{abstract}

Keywords Deep groundwater · Hydrochemical characteristics $\cdot$ Isotopic analysis $\cdot$ Renewable property $\cdot$ Groundwater contamination

\section{Introduction}

A deep confined aquifer refers to groundwater stored deeply underground between two impermeable or low permeability layers and which usually have a limited hydraulic connection to the surface water (Nandimandalam 2012). This kind of aquifers are generally formed during geologically long periods of time under specific climatic conditions. They have very limited recharge sources, renews extremely slowly, has a long supply cycle, and is hardly influenced by climatic fluctuations (Stober and Bucher 1999; Michael and Voss 2008; Alaya et al. 2014). As most deep confined aquifers contain groundwater under positive pressure, they are also sometimes referred to artesian or sub-artesian aquifers (Mallamace et al. 2013). Due to the excellent quality of the water in deep confined aquifers, countries and regions around the

Jin Lin

jinl@nhri.cn

1 National Key Laboratory of Water Resources and Hydraulic Engineering, Nanjing Hydraulic Research Institute, Nanjing 210029, China world facing water shortage are placing much impetus on their development and utilization (Ji and Wang 1999; Zhang et al. 2000; Margat et al. 2005).

There are a lot of debates on the resource attributes of deep groundwater. Recent researches mainly focus on whether we are "mining non-renewable groundwater resources", or whether these resources can be used in a sustainable manner. At present, there are two viewpoints: (1) the deep groundwater is formed during the geological history and there is basically no or negligible replenishment. The development of groundwater is "groundwater extraction" of storage, because it is non-renewable, which is similar to the stored mineral resources (Margat and Saad 2010; Maliva and Missimer 2012); (2) The groundwater system is renewable, because the development of deep groundwater has changed the flow pattern of groundwater, which accelerates the circulation rate of groundwater and induces the recharge of groundwater despite the slow flow of groundwater under natural conditions (Christen and Khan 2002; Foster and Loucks 2006). These two views reflect the different understanding of a quaternary confined aquifer system in the study area, which is directly related to the rational 
development and utilization of groundwater in this area and the development of planning and management methods for groundwater development.

In theory, all water resources are renewable. This is also the case for deep groundwater resources which are to a certain extent renewable. The key to rational use and effective protection of deep groundwater resources lies in a correct understanding of deep groundwater circulation. Deep groundwater is a comprehensive reflection of regional groundwater recharge, runoff, and drainage conditions. It is also an important basis for evaluating and managing regional groundwater resources, and provides the scientific basis for developing a groundwater development model (Lloyd 1990; Chatterjee and Purohit 2009). Environmental isotopes can be used to effectively trace the water cycle, such as indicating the source of water, the amount of water under different environmental conditions, determining the age of water, and recording water-rock interactions, especially in the study of groundwater and its renewability. Yurtsever and Payne (1979) analyzed the leakage of saltwater to the phreatic aquifer in deep confined aquifers in southwestern Qatar based on the data of ${ }^{18} \mathrm{O}$ and D isotopes; Kwang et al. (1999) calculated the precipitation infiltration recharge of groundwater in Cheju Island, South Korea by mass balance equation based on the range of D surplus in summer and winter in most of Northeast Asia. In 1996, the IAEA developed an international cooperative research project and studied groundwater renewability in water shortage areas such as Syria, the United Kingdom, Senegal, Nigeria, Mexico, Egypt, Australia, India, South Africa, Tunisia, and Jordan. Deep groundwater is recharged primarily with local precipitation from shallow unconfined aquifers by inflow through weakly permeable layers, or through the lateral supply of precipitation outside the confined aquifer region due to the dip of the strata. It is important to note that while the recharge of the aquifer increases water volume, it can also transport pollutants from the land surface and in shallow aquifers into deep confined aquifers, which is the reason why contamination prevention should be a necessary aspect of water resource management (Burgess et al. 2010; Hasiniaina et al. 2010; Kouassy and Ndam 2016).

Currently, deep groundwater is still the main water source for most cities in the HRB, which accounts for more than $98 \%$ of the water consumption in several cities. Since geological history, groundwater has evolved with glacial recessions, transgressions, regressions and climate changes. However, only a few decades of groundwater exploitation has changed the groundwater flow and cycle characteristics, fundamentally, in terms of natural recharge, runoff and drainage. The change is primarily due to human interference (Liu et al. 2005; Burgess et al. 2010; Michael and Voss 2008).

The way and amount of deep groundwater recharge have also been fundamentally changed by anthropogenic factors, leading to environmental problems such as the development of deep groundwater depression cones at the center of cities, deterioration in deep groundwater quality, etc. In this study, the renewable property and contamination status of deep groundwater is determined based on the results of the field geological survey and water sample analysis. It aims to provide reasonable suggestions for the development, utilization, and management of groundwater resources, especially for deep groundwater resources in the HRB. Furthermore, the analysis results can provide basic data for water environment protection.

\section{Description of the study area}

\section{Overview of the study area}

The HRB (including the Shandong Peninsula) is located in the southern-northern climate transition zone of eastern China. It lies between the Yangtze and Yellow Rivers, and is located at longitude $111^{\circ} 55^{\prime}-122^{\circ} 45^{\prime}$ east and latitude $30^{\circ}$ $55^{\prime}-38^{\circ} 20^{\prime}$ north. It is bounded by the Tongbai Mountain and Funiu Mountain in the west, Dabie Mountain, Jianghuai Hill, Tongyang Canal, Rutai Canal south bund and Yangtze River basin in the south, the Yellow River south bund and Yellow River basin in the north, and the Yellow Sea and Bohai Sea in the east. It covers an area of about $330,000 \mathrm{~km}^{2}$ across 47 prefecture-level cities in five provinces, including Hubei, Henan, Anhui, Jiangsu, and Shandong (Yu 2014) (Fig. 1).

The annual average temperature of the river basin varies between 13.2 and $15.7^{\circ} \mathrm{C}$, with temperatures higher in the south and lower in the north. The annual average monthly maximum temperature is about $27{ }^{\circ} \mathrm{C}$ (July or August), while the annual average monthly minimum temperature is about $0{ }^{\circ} \mathrm{C}$ (January). The average annual precipitation is $700 \mathrm{~mm}-900 \mathrm{~mm}$; and the average annual evaporation is $1000 \mathrm{~mm}-1300 \mathrm{~mm}$.

In the 1970s, the average annual groundwater exploitation in the HRB was 900 million $\mathrm{m}^{3}$. By the 1990s, the annual average amount of groundwater exploitation in the HRB had increased to 1.78 billion $\mathrm{m}^{3}$. After 2010, the average annual groundwater in this area increased to 2.75 billion $\mathrm{m}^{3}$, which is more than double the total amount of mining in the 1970s. The deep groundwater is mainly used for urban and industrial water consumption, with an annual mining capacity of 787 million $\mathrm{m}^{3}$, accounting for $28.6 \%$ of the total groundwater extraction.

\section{Demarcation of study area}

In this study the center of the groundwater depression cone and the main surface expression of the water basin is taken 


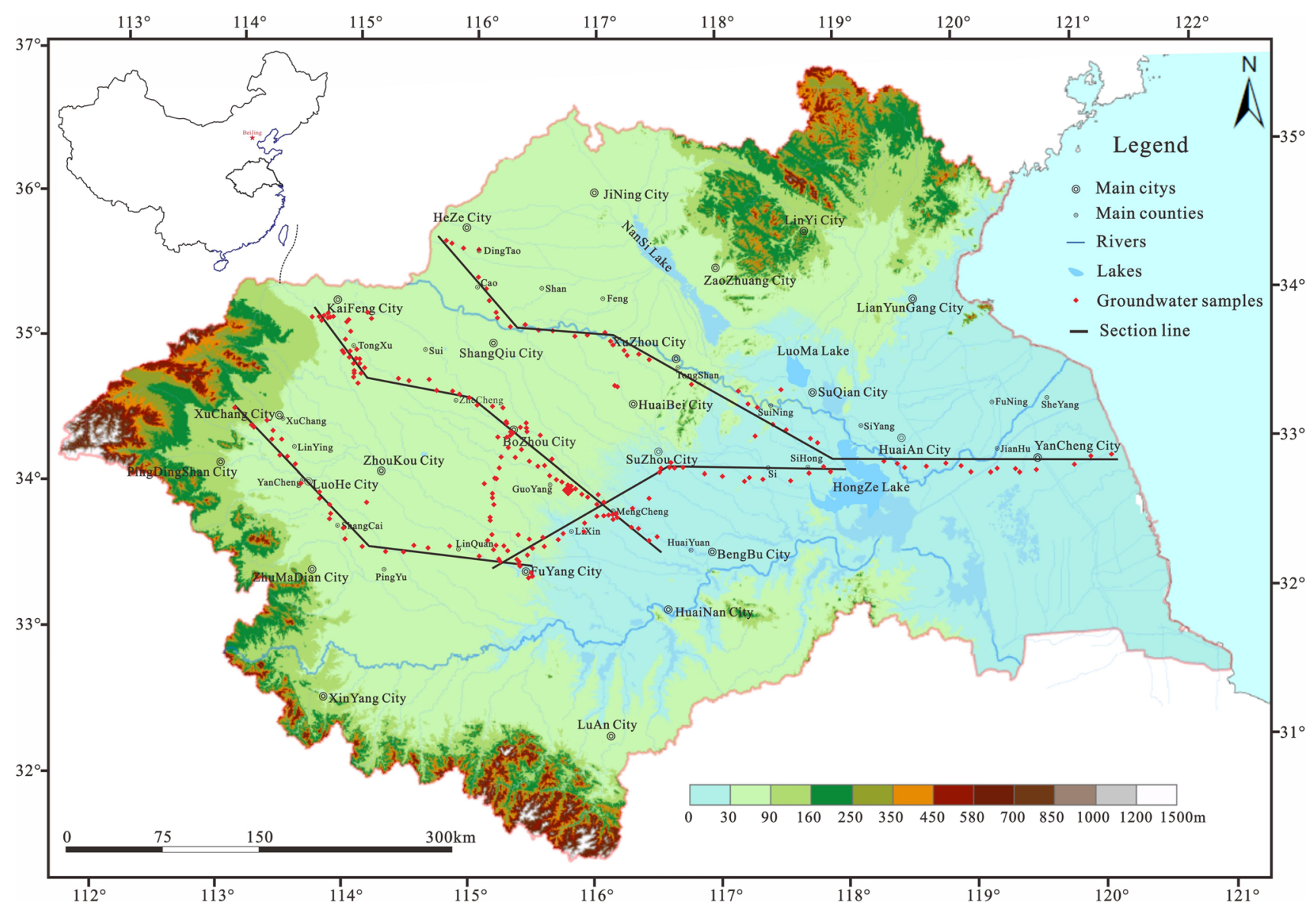

Fig. 1 Location of study area and the groundwater samples. In this figure, the location of the sampling points (red diamond square), three vertical profiles and one horizontal profile

as the center (i.e., the main mining area of deep groundwater), and lines are drawn along the axis of the basin starting from the core point; the points and lines in different cities are connected to form one horizontal and three vertical profiles (Fig. 1). The horizontal profile refers to a starting point from the Eastern Henan Plain and passes through the Yuxi mountainous area, that is, a source of lateral supply of deep groundwater in the Eastern Henan Plain and Northern Anhui Plain, and traverses different deep groundwater systems of the HRB. The selected route passes from Fuyang Taihe border to Lixin, Mengcheng, Suzhou, Lingbi and Sihong County of Suqian City, and has a total length of approximately 270 km (i.e., profiles IV-IV' in Fig. 1).

The three vertical profiles refer to:

1. Shayinghe River Profile Starting from Xuchang, passing through Linying County, Luohe City and Zhumadian City, to reach Fuyang Taihe border, with a total length of about 370 km (profiles I-I' in Fig. 1);

2. Guohe River Profile Starting from Kaifeng, passing through Zhecheng County, Guoyang County and
Mengcheng, to reach Huaiyuan County of Bengbu city, with a total length of about $320 \mathrm{~km}$ (profiles II-II' in Fig. 1);

3. Ancient Yellow River Profile Starting from Heze, passing through Caoxian County, Shanxian County, Fengxian County, Xuzhou, Suining County and Sihong, to reach Huaian, Sheyang County of Yancheng, with a total length of about $520 \mathrm{~km}$ (profiles III-III' in Fig. 1).

\section{Definition of deep groundwater in HRB}

The word "deep" does not refer to the "depth" per se. It means the relatively slow recharging speed comparing with the active water cycle in shallow groundwater. Deep groundwater mainly refers to groundwater in a confined aquifer, and can also include groundwater in a semi-confined aquifer which has a potentiometric head that lies beneath the land surface, or is no longer confined due to overexploitation (Pedersen et al. 2014).

A wide range of unconsolidated porous sediments distribute in the HRB, lying 30-55 m under the surface, as well 
as a cohesive sediment layer on the surface with a thickness of 14-20 m. Groundwater at a depth of $50 \mathrm{~m}$ is characterized as being from a "shallow"aquifer and water at a depth of 50-300 $\mathrm{m}$ is characterized as being from a "medium" to "deep" aquifer in Henan. As the depth of phreatic groundwater and the level I semi-confined aquifer in Jiangsu is less than $50 \mathrm{~m}$, it is generally referred to as shallow groundwater, and the level II to IV confined aquifers at a depth of more than $50 \mathrm{~m}$ are jointly referred to as deep groundwater.

Based on the results of the HRB Environmental Geological Survey (Cheng 2011) and the results of hydrogen and oxygen isotope variation with depth and ${ }^{14} \mathrm{C}$ dating, we consider a depth of about $50 \mathrm{~m}$ below the surface as the boundary of shallow aquifer groups and deep aquifer groups. Accordingly, the groundwater in the shallow aquifer groups and deep aquifer groups are referred to shallow groundwater and deep groundwater, respectively.

\section{Sampling and analysis method}

\section{Data collection}

In this study, the required groundwater samples were directly collected from deep and shallow wells that are continuously pumped for water supply. Concurrently, the dynamic water level depth of deep groundwater supply wells were also measured if conditions permitted.

Some large-diameter agricultural shallow wells that were not being used for irrigation were also sampled. The collected water samples were filtered using 0.22-micron filter membrane, packaged in cleaned sampling bottles, and analyzed at the laboratories of the Nanjing Hydraulic Research Institute. To guarantee water quality, the samples were refrigerated during the entire transportation and storage process.

A total of 390 water samples were collected in this study, including 216 deep groundwater samples and 174 shallow groundwater samples.

\section{Analysis method}

The analysis contents considered in this study are as follows:

1. Basic parameters (including water temperature, $\mathrm{pH}$ value, dissolved oxygen, electrical conductivity EC, etc.). These parameters were measured in the field during sampling.
2. Major ion analysesHydrochemical (including $\mathrm{K}^{+}, \mathrm{Na}^{+}$, $\mathrm{Ca}^{2+}, \mathrm{Mg}^{2+}, \mathrm{NO}_{3}{ }^{-}, \mathrm{F}^{-}, \mathrm{Cl}^{-}, \mathrm{SO}_{4}{ }^{2-}, \mathrm{HCO}_{3}{ }^{-}, \mathrm{CO}_{3}{ }^{2-}$ and other hydrochemical ions as well as elements such as $\mathrm{Si}$, $\mathrm{U}$, etc.).

3. Isotope analysis and chemical tracers (including stable isotopes such as 180 and $\mathrm{D}$ ).

Concentration were measured on site. Concentration of positive ions such as $\mathrm{K}^{+}, \mathrm{Na}^{+}, \mathrm{Ca}^{2+}$ and $\mathrm{Mg}^{2+}$ were measured by inductive coupling and other plasma emission spectroscopy ICP-OES techniques. Concentration of negative ions such as $\mathrm{NO}_{3}{ }^{-}, \mathrm{F}^{-}, \mathrm{Cl}^{-}, \mathrm{SO}_{4}{ }^{2-}$, etc. were measured by ion chromatography ICS-2100. As the concentration of $\mathrm{Si}$ was measured useing a SKALAR San + + flow injection analyzer. The stable isotopes such as ${ }^{18} \mathrm{O}$ and Dwere measured useing a LGR liquid water isotope laser mass spectrometer.

\section{Results and discussion}

\section{Identification of deep groundwater system}

Groundwater systems can be generally categorized based on differences in their chemical compositions or by analyzing isotopic trend line relationship or isotope range. In this study, as the sampling range is very broad (a total 14 cities and 35 counties), there are relatively very few sampling points in each county, and due to objective limitations in individual counties, the trend lines to represent the whole system. As a result of this, the deep groundwater system was categorized mainly based on isotope ranges in this study (Gu 2011).

Due to the wide scope of this project, the large quantity of data that were collected, the risks of data mix-ups, and the difficulty in identifying the isotopic characteristics of deep groundwater samples from each county, the isotopic characteristics in each county was first identified, and the overall characteristics were analyzed. Figure 2 shows the distribution of hydrogen and oxygen isotopes in water samples from all 35 counties. It illustrates that 180 and $D$ in deep groundwater in most of the counties have relatively centralized distribution, and can be approximately divided into upper and lower levels by taking $\delta^{18} \mathrm{O}=-8.5$ as the boundary (Fig. 2).

In fact, the threshold of different groundwater systems based on isotope characteristics is not arbitrarily given. The boundary line is not only the dividing line of the isotope value distribution (the upper and lower isotope values), but 

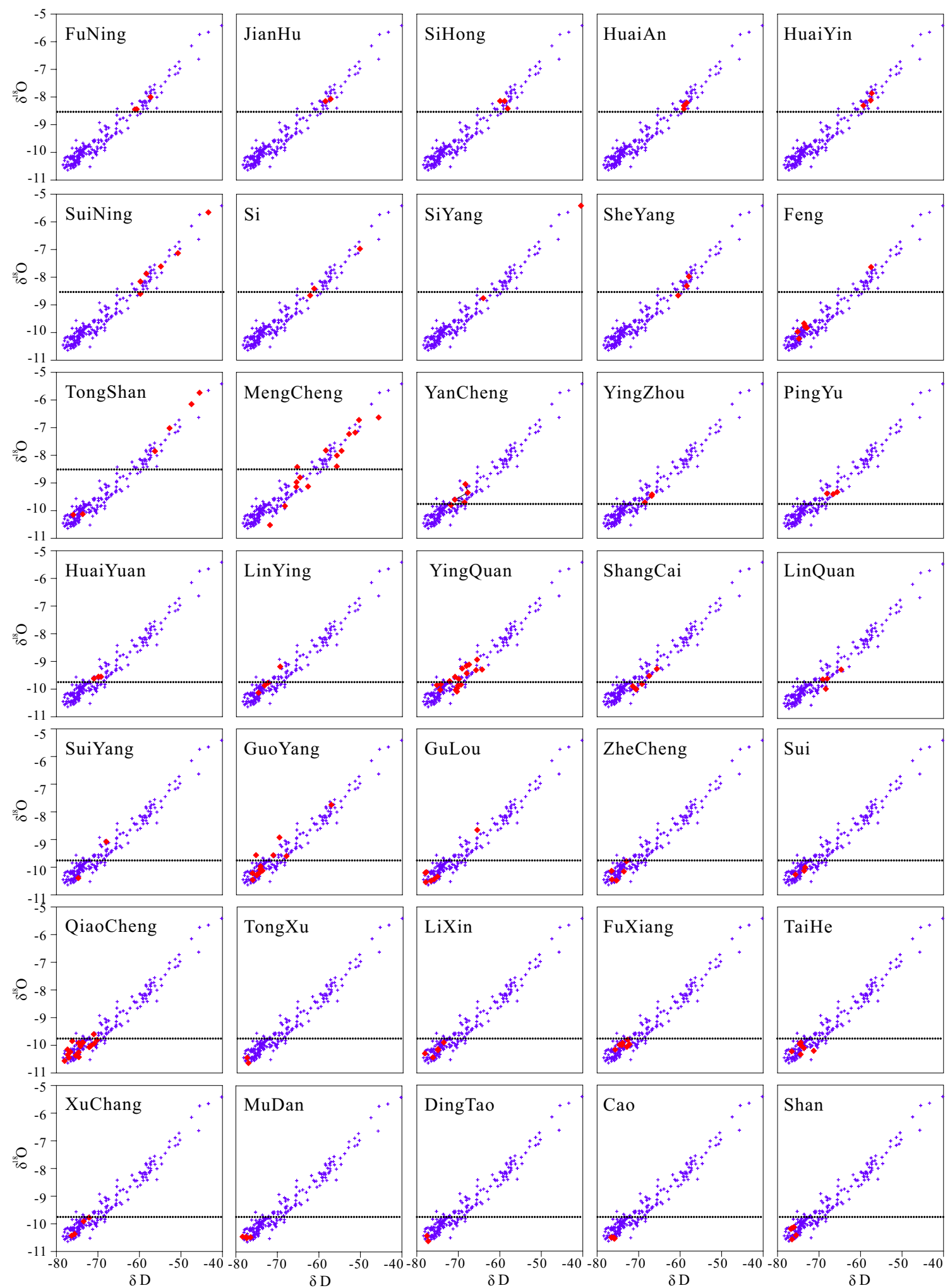

Fig. 2 Distribution of hydrogen and oxygen isotopes in water samples from HRB. The blue cross (+) represents the analysis results of all deep groundwater samples and the red diamond $(\lambda)$ represents the analysis results of deep groundwater samples in the county. HRB can be divided into the Ancient Yellow River, the Shayinghe river and the Guohe river groundwater system by the $\delta 18 \mathrm{O}=-8.5$ and -9.75 . 
also separation line of geographical location in each county. According to the category, there are about 11 counties (including a few parts of Mengcheng and Tongshan county) that belong to the Ancient Yellow River groundwater system and the other 24 counties are not underlain by groundwater that belongs to this flow system. The remaining 24 counties are divided into the Shayinghe river groundwater system and the Guohe river groundwater system by the $\delta^{18} \mathrm{O}=-9.75$ boundary and the sampling sites (Fig. 2). And the final category of deep groundwater system in HRB is shown in Fig. 3.

\section{Relationship between deep groundwater and shallow groundwater}

\section{Relationship analysis of electrical conductivity and isotopes of deep and shallow groundwater}

The measurement results of isotopes and main hydrochemical indicators of deep and shallow groundwater in the three sub-systems are shown in Table 1 and Fig. 4. It can be seen that the conductivity of deep groundwater and shallow

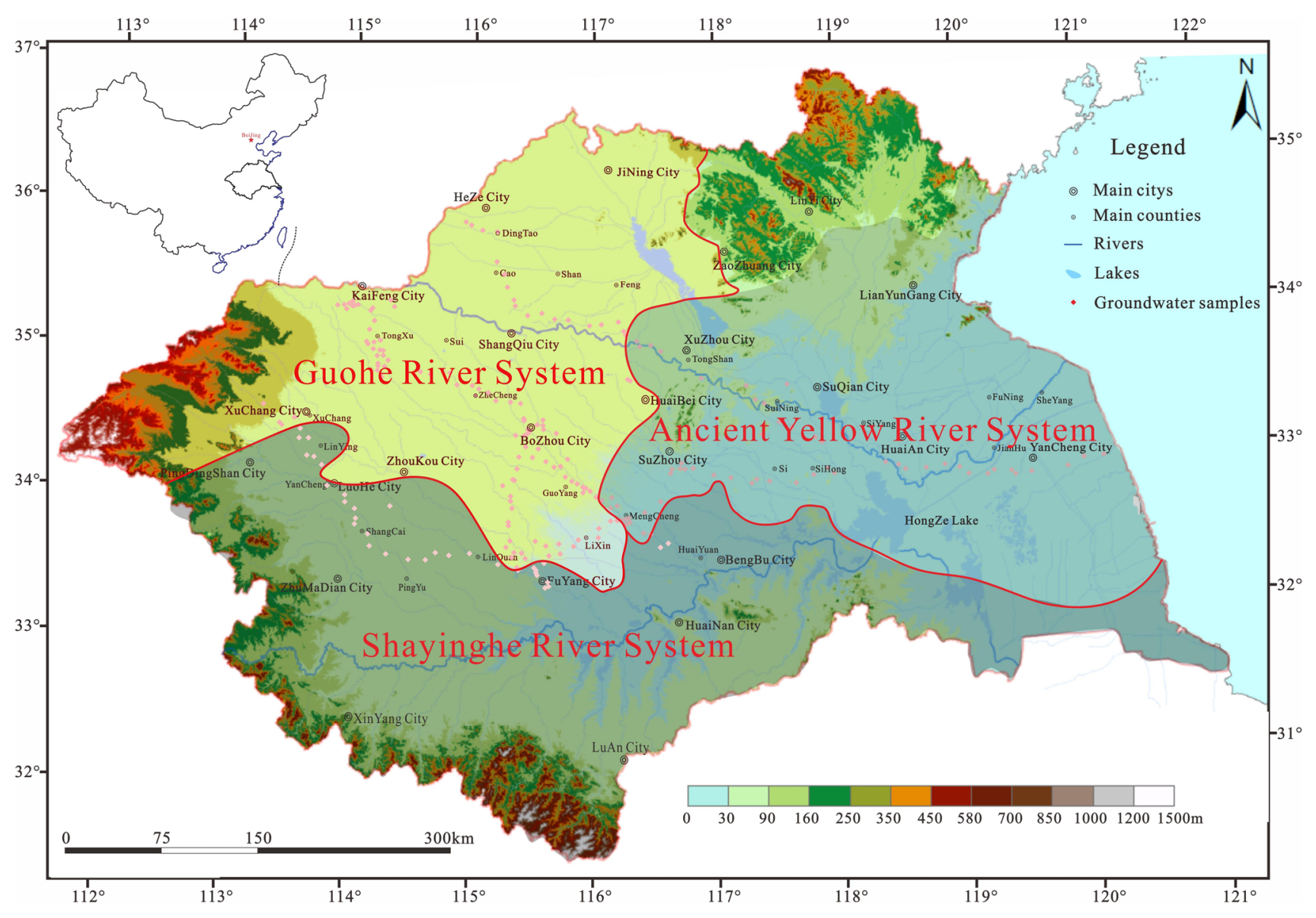

Fig. 3 Division of deep groundwater system in HRB

Table 1 Isotopic and chemical data of shallow and deep groundwater from three subsystem in HRB

\begin{tabular}{|c|c|c|c|c|c|}
\hline \multirow[t]{2}{*}{ Sub-system } & \multicolumn{4}{|c|}{ Isotopic and hydrochemical composition content (mean \pm standard deviation) } & \multirow[t]{2}{*}{ Water type } \\
\hline & $\delta \mathrm{D}(\% \circ)$ & $\delta^{18} \mathrm{O}(\% o)$ & $\mathrm{EC}(\mu \mathrm{s} / \mathrm{cm})$ & TDS (mg/L) & \\
\hline Shayinghe system (shallow) & $-56.4 \pm 4.2$ & $-8.1 \pm 0.5$ & $1193.7 \pm 516.0$ & $976.3 \pm 360.4$ & $\mathrm{HCO}_{3} \cdot \mathrm{Cl}-\mathrm{Ca}$ \\
\hline Shayinghe system (deep) & $-68.1 \pm 1.9$ & $-9.5 \pm 0.3$ & $820.3 \pm 213.7$ & $686.7 \pm 138.3$ & $\mathrm{HCO}_{3}-\mathrm{Na} \cdot \mathrm{Ca}$ \\
\hline Guohe system (shallow) & $-59.7 \pm 4.9$ & $-8.2 \pm 0.7$ & $1424.0 \pm 583.6$ & $1185.9 \pm 457.7$ & $\mathrm{HCO}_{3}-\mathrm{Na} \cdot \mathrm{Mg} \cdot \mathrm{Ca}$ \\
\hline Guohe system (deep) & $-74.5 \pm 2.7$ & $-10.1 \pm 0.4$ & $1240.3 \pm 372.1$ & $1039.2 \pm 236.1$ & $\mathrm{HCO}_{3} \cdot \mathrm{Cl}-\mathrm{Ca}$ \\
\hline Ancient Yellow River system (shallow) & $-51.6 \pm 7.7$ & $-7.1 \pm 1.1$ & $1280.5 \pm 1027.2$ & $968.1 \pm 705.4$ & $\mathrm{HCO}_{3} \cdot \mathrm{Cl}-\mathrm{Na} \cdot \mathrm{Ca} \cdot \mathrm{Mg}$ \\
\hline Ancient Yellow River system (deep) & $-55.9 \pm 5.1$ & $-7.7 \pm 0.8$ & $1464.0 \pm 214.8$ & $746.3 \pm 172.2$ & $\mathrm{HCO}_{3} \cdot \mathrm{Cl}-\mathrm{Na} \cdot \mathrm{Ca}$ \\
\hline
\end{tabular}



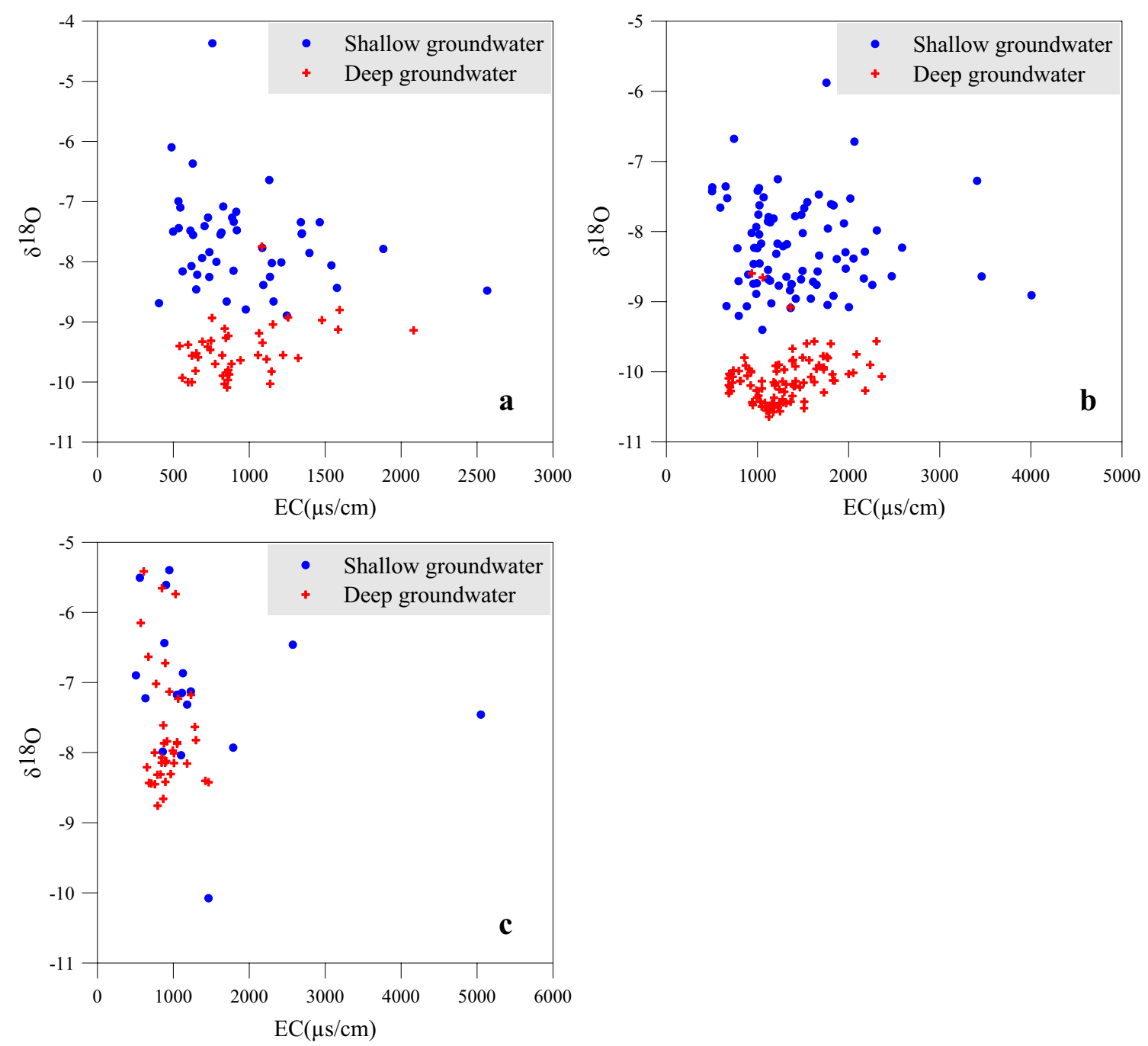

Fig. 4 Comparison of electrical conductivity and isotopes between shallow and deep groundwater in Shayinghe River System (a), Guohe River System (b) and Ancient Yellow System (c)

groundwater are quite different in the Guohe River System and Shaying River System which are upstream of the basin. The EC of deep water is lower than that of shallow water, indicating that the shallow groundwater system has almost no hydraulic connection with the deep groundwater system, where the viscous formation plays an obvious role. In addition, the standard deviation of conductivity in shallow water samples is significantly higher than that in deep water samples, indicating that shallow groundwater is closely related to surface water, and is greatly affected by precipitation and surface sewage, resulting in obvious differences in shallow groundwater quality (Fig. 5).

Electric conductivity (EC), which represents the total dissolved solids (TDS) in the water on one hand, can be applied to reveal the differences in flow paths and residence times during the water circulation circumstances. With the prolonged flow path and residence time, increased EC can be observed in both shallow and deep aquifers due to the continuous dissolution of soluble constituents in surrounding rocks and soils, as well as the resulting ion exchanges. The EC values in the deep aquifer of the Ancient Yellow River System are the highest, followed by the EC values in the deep aquifer of Guohe River System and in the deep aquifer of Shaying River System. Based on the EC measurements in different aquifers, it can be referred that the groundwater flow path in the deep aquifer was from Shaying River System to Guohe River System to Ancient Yellow River System, which is consistent with the general geography in the HRB.

There is a large overlap of the EC values in the shallow and deep groundwater in the Ancient Yellow River System due to the increased water depth in the deep aquifer downstream of the Huai River Basin, thus resulting in more frequent interaction between the shallow and deep groundwater. 

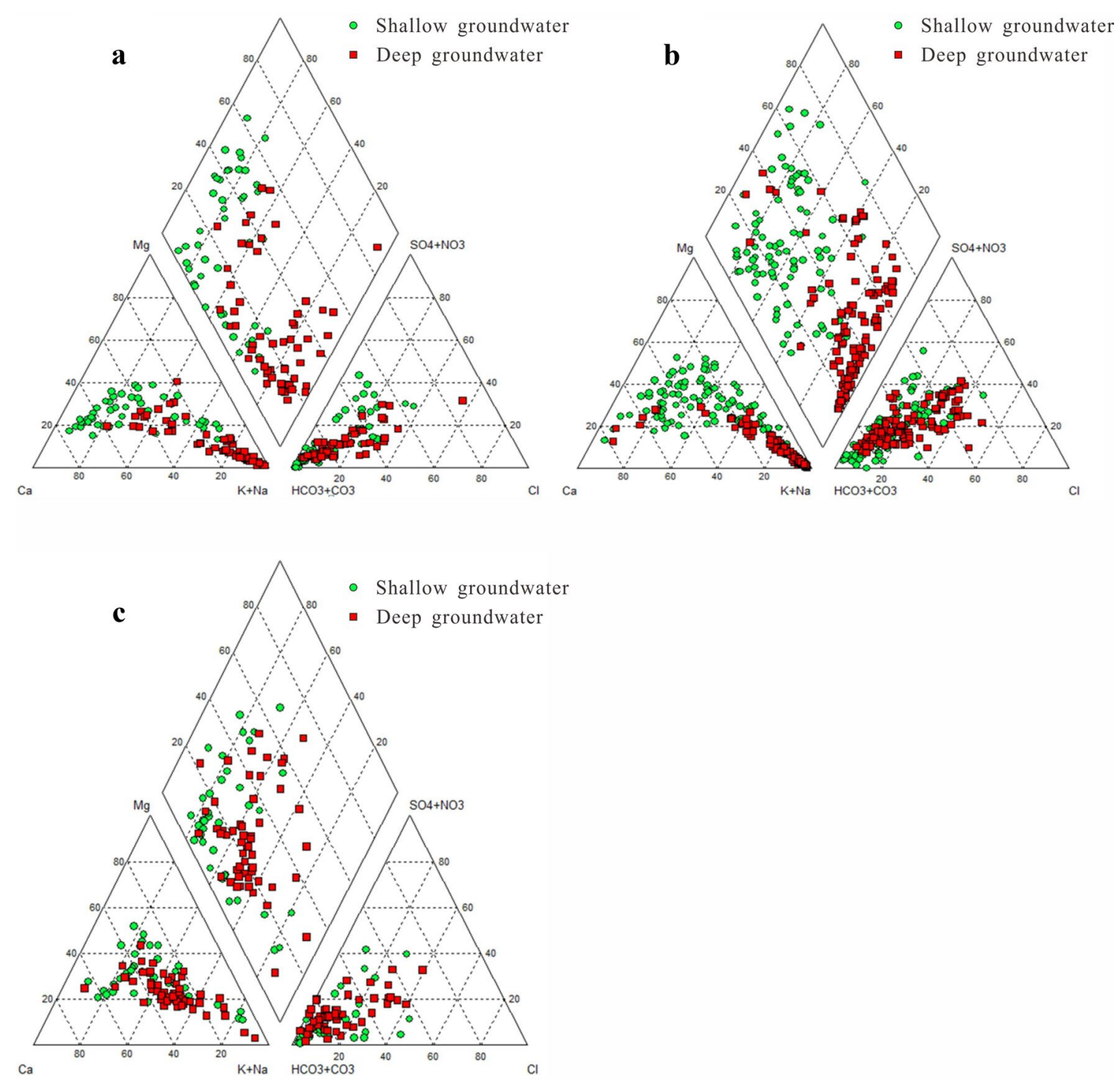

Fig. 5 Comparison of hydrochemical characteristics between shallow and deep groundwater in Shayinghe River System (a), Guohe River System (b) and Ancient Yellow System (c)

Based on the standard deviation of EC of the Ancient Yellow River shallow groundwater samples, the deep and shallow groundwater of the Ancient Yellow River is closely related to surface water, which represents a higher renewable capacity compared to groundwater from other two sub-watersheds. Meanwhile, water quality from the Ancient Yellow River aquifer is worse than the other two based on the higher EC values, leading to higher contamination risk.

\section{Hydrochemical relationship analysis of deep and shallow groundwater}

By comparing hydrochemical analysis of the shallow and deep groundwater in the same region, it is possible to determine whether there is a hydraulic connection between the shallow and the deep groundwater. Simultaneously, it is useful to determine if the deep groundwater is being recharged presently or dose it has contaminants (Appelo and Postma 2005).

There are obvious differences in solubility and total dissolved solids between the deep and shallow groundwater in Shayinghe River and Guohe River groundwater systems, and an obvious boundary exists, which clearly indicates that there is hardly any hydraulic connection between the deep groundwater and the shallow groundwater and its viscous strata. However, the relatively poor differentiation between the Ancient Yellow River deep groundwater system and shallow groundwater indicates that there is an obvious hydraulic connection. 
Groundwater in the HRB is dominated by $\mathrm{HCO} 3-\mathrm{Na} \bullet \mathrm{Ca}$ type. The water contains $50 \%-80 \%$ milliequivalent of $\mathrm{HCO}_{3}{ }^{-}$, while $\mathrm{Cl}^{-}$accounts for less than $30 \%$ milliequivalent among those anions. $\mathrm{Na}^{+}$and $\mathrm{Ca}^{2+}$ are the dominant cations in the groundwater.

Based on the EC and chemistry results of groundwater from the Shaying River sub-watershed deep aquifer, the dominant $\mathrm{HCO}_{3}{ }^{-}$and $\mathrm{Ca}^{2+}$ represent precipitation recharging the aquifer, which is along with the fact that Shaying River sub-watershed is located in the upstream portion of the HRB. With the observed increasing percent of $\mathrm{Cl}^{-}$and $\mathrm{Na}^{+}$in groundwater in the Ancient Yellow River System, it is characterized by groundwater in the drainage area of the coastal zone.

\section{Relationship analysis of isotopic characteristics of deep and shallow groundwater}

Table 1 shows that values of $\delta \mathrm{D}$ and $\delta^{18} \mathrm{O}$ of the deep aquifer are smaller than the shallow aquifer in three sub-systems. Furthermore, the values of $\delta \mathrm{D}, \delta^{18} \mathrm{O}$ of the deep aquifer are located at the bottom right of the global meteoric water line (GMWL)and the local meteoric water line (LMWL). The reasons for this phenomenon are: (1) the modern evaporation fractionation makes it is easier to keep the water molecules with heavy isotopes in the shallow aquifer, while the deep aquifer dose not affected by it, (2) there is a certain amount of paleoprecipitation with lower values of $\delta \mathrm{D}$ and $\delta^{18} \mathrm{O}$. (3) Shaying river and Guo river are located in the upper reaches of the HRB, and their high altitude can also cause the lower values of the stable isotope in groundwater.

Figure 6 shows that almost all of the values of $\delta D-\delta{ }^{18} \mathrm{O}$ of the deep and shallow aquifers in the three sun-basins are located above the same trend line, which means they have the same mainly recharge source, the local precipitation. The obvious differences in values of hydrogen and oxygen isotopes of the deep and shallow aquifers can also show that the deep and shallow groundwater systems in these two sub-systems are relatively independent. While there are no clear boundaries of the values of $\delta \mathrm{D}-\delta^{18} \mathrm{O}$ in the deep and shallow aquifers of the Ancient Yellow River System. Even, part of the hydrogen and oxygen isotopes are located above the MWL. Both of them show that the deep groundwater interacts closely with the shallow water and precipitation.

Comparing with the other two sub-systems, the deep aquifer of Guohe River System has the lowest value of
Fig. 6 Comparison of isotopic characteristics between shallow and deep groundwater in Shayinghe River System (a), Guohe River System (b) and Ancient Yellow System (c)
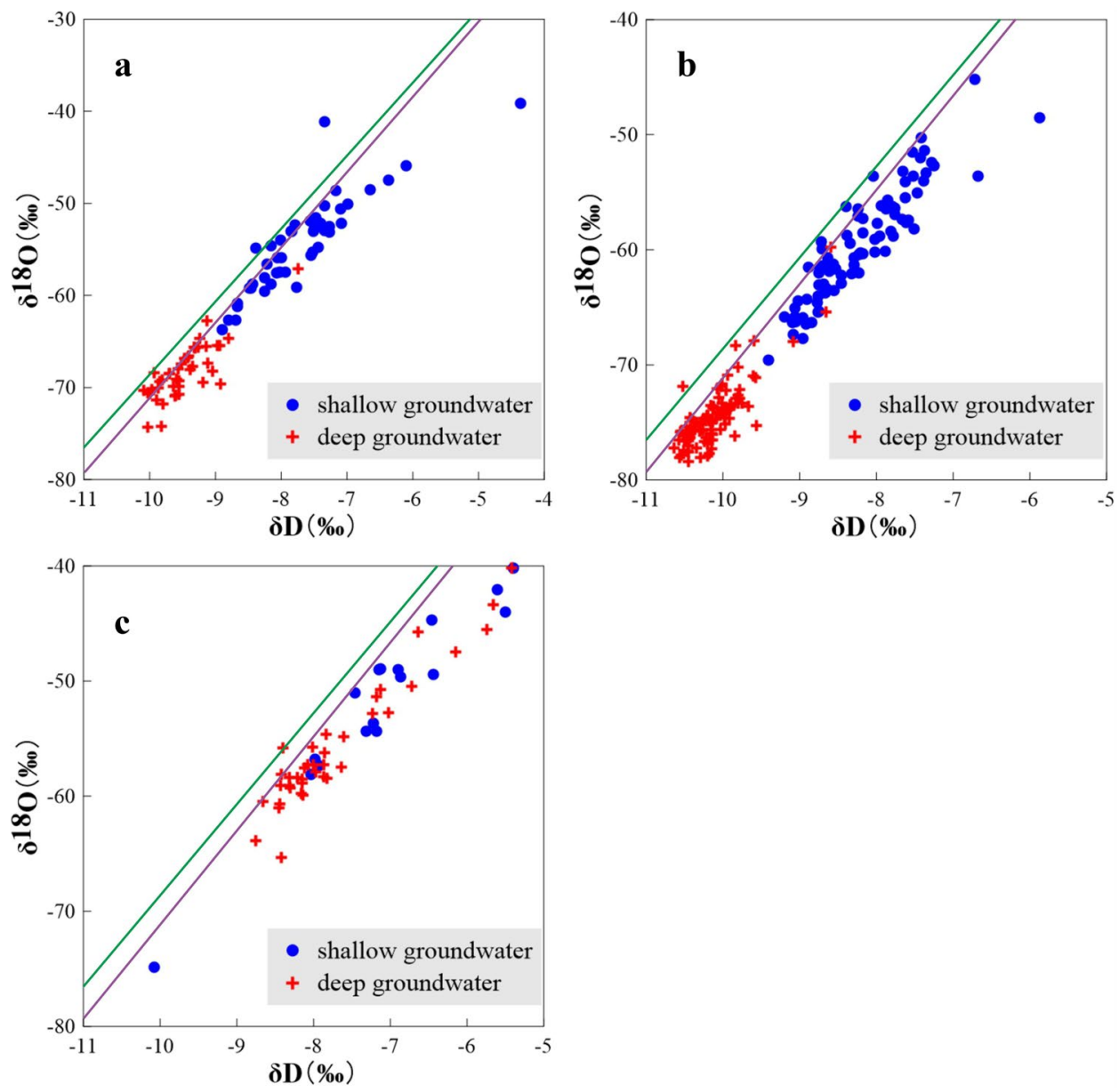
hydrogen and oxygen isotopes and deep aquifer of Ancient Yellow River System has the highest value of hydrogen and oxygen isotopes. It is slightly different from the direction of groundwater flow that the stable isotopes of Guohe River System are relatively poor, which shows that the connection between deep and shallow aquifer is the worst. It can be inferred that the overlying aquitard of Guohe River System is thicker or more continuous.

\section{Analysis of the renewability of the deep groundwater}

Deep groundwater is a mixture of several different water sources that have been mixed in different proportions. The identification of groundwater recharging sources is actually simpler to resolve than the reverse problem of determining mixing proportions, because the end members can be identified from the groundwater mixing system. Each end member can be calculated by Eq. (1):

$\alpha_{A}=\frac{\left(Y_{B}-Y_{C}\right)\left(X_{i}-X_{C}\right)-\left(X_{B}-X_{C}\right)\left(Y_{i}-Y_{C}\right)}{\left(Y_{B}-Y_{C}\right)\left(X_{A}-X_{C}\right)-\left(X_{B}-X_{C}\right)\left(Y_{A}-Y_{C}\right)}$

$\alpha_{B}=\frac{\left(Y_{A}-Y_{C}\right)\left(X_{i}-X_{C}\right)-\left(X_{A}-X_{C}\right)\left(Y_{i}-Y_{C}\right)}{\left(Y_{A}-Y_{C}\right)\left(X_{B}-X_{C}\right)-\left(X_{A}-X_{C}\right)\left(Y_{B}-Y_{C}\right)}$

$\alpha_{C}=1-\alpha_{A}-\alpha_{B}$,

where, $A, B$, and $C$ represent three end members of water sample $i . \alpha_{A}, \alpha_{B}$, and $\alpha_{C}$ represent the proportion of three water sources of water sample $i$, respectively. $X$ and $Y$ are isotopic or chemical index content.

$X$ and $Y$ in the endmember analysis of this project are $\delta^{18} \mathrm{O}$ and $\mathrm{Si}$. Similar to uranium, silicon is a widely distributed element in the earth's crust and is ubiquitous. Silicic acid is a fixed component of natural water and it varies in concentration. Since different water sources have different formation processes and each has its own evolutionary history when it reaches the groundwater system, the silica content of the water will also vary. Like uranium, the concentration of silicon in precipitation is very low and this element can undergo a range of chemical reactions in the subsurface. Therefore, silicon, together with the oxygen isotope that makes up the water molecule, can be used as a tracer to identify different water sources.

The foregoing has shown that the relationship between deep groundwater and shallow groundwater is weak in both the Shayinghe River System and the Guohe River system, while the Ancient Yellow River groundwater system is relatively strong. The end-member $A$ is the recharge from precipitation, which is the precipitation or the shallow groundwater from precipitation in the vicinity; B is the groundwater flowthrough, which is the shallow water formed by the precipitation in a distant upgradient area. $C$ is the storage of deep groundwater, which is the modern deep groundwater formed by the lateral replenishment of the historical period and the local infiltration replenishment. $A$ and $B$ can be considered as the system renewable rate, and A can be considered as the recent renewable rate (that is, the amount that can be renewed in short time frame of several months or years).

The results of the three system renewable capabilities calculated by the end member method are shown in Table 2. In general, the deep groundwater systems in the HRB are rarely recharged by precipitation and throughflow, mainly because most of the sampling depths are more than $200 \mathrm{~m}$ that can hardly be replenished by shallow water. Among the three systems that were categorized, the deep groundwater system of the Ancient Yellow River has the strongest ability to be subjected to precipitation and throughflow, with an average of 0.61 , which is far greater than the deep groundwater system of the Shayinghe River and the Guohe River flow systems. On the one hand, groundwater samples from the deep flow component of Ancient Yellow River flow system were obtained from a relatively shallow depth (the general sampling depth was less than $200 \mathrm{~m}$ ). On the other hand, there is still a phenomenon of over-draining deep groundwater in the Ancient Yellow River groundwater system including Huai' an and Yancheng, which promotes vertical leakage and lateral groundwater inflow to cones of depression.

\section{Deep groundwater contamination parameters and its spatial distribution}

Total dissolved solid (TDS) is an important indicator reflecting the quality of groundwater. The TDS distribution of deep and shallow groundwater systems in HRB is shown in Figs. 7 and 8. It can be seen from the figures that the quality of shallow groundwater in the HRB is generally poor. In addition, the TDS concentration in most areas exceeds the national quality standard class III for groundwater. Especially shallow groundwater in Kaifeng, Shangqiu, and Huaibei of Guohe River system and Suqian, Huai' an and other cities of the ancient Yellow River system is no longer suitable for usage, forcing people to shift the target of groundwater exploitation from shallow to deep.

Table 2 Renewable capabilities of the three deep groundwater systems in the HRB

\begin{tabular}{llll}
\hline Deep groundwater system & $\begin{array}{l}A(\%) \\
\text { precipita- } \\
\text { tion }\end{array}$ & $\begin{array}{l}B(\%) \\
\text { lateral } \\
\text { recharge }\end{array}$ & $\begin{array}{l}C(\%) \text { storage of } \\
\text { deep ground- } \\
\text { water }\end{array}$ \\
\hline Ancient Yellow River & 36 & 25 & 39 \\
Shayinghe & 22 & 22 & 56 \\
Guohe & 12 & 23 & 65 \\
\hline
\end{tabular}

$A$ is the recharge of precipitation, $B$ is the lateral recharge, $C$ is the storage of deep groundwater. $A$ and $B$ can be considered as the system renewable rate, and $A$ can be considered as the recent renewable rate 

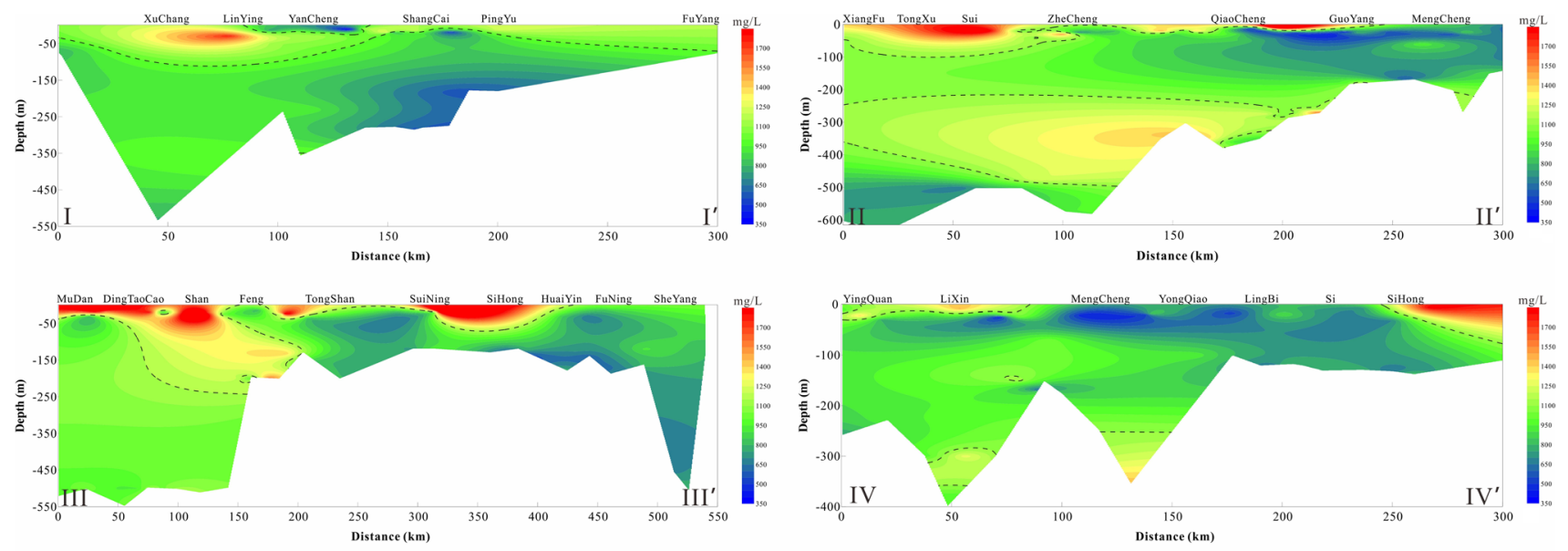

$1000 \mathrm{mg} / \mathrm{L}$, The class III of environmental quality for groundwater(GB/T 14848-2017)

Fig. 7 Spatial distribution of TDS concentration along four profiles. The dotted line (dashed line) is the isoline of TDS concentration of $1000 \mathrm{mg} / \mathrm{L}$, it can be seen from the figure, where the TDS concentration exceeds the standard on the profiles
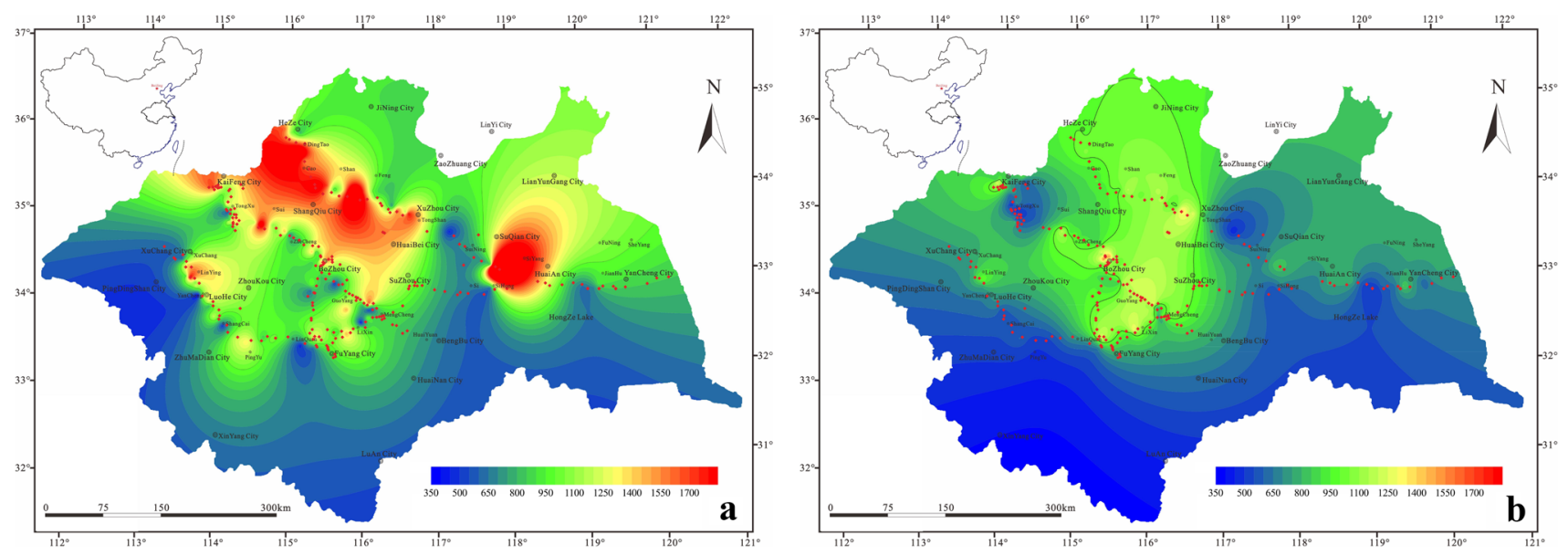

Fig. 8 Distribution of TDS concentration in shallow groundwater (a) and deep groundwater (b) of HRB

Compared with the shallow groundwater, the deep groundwater quality is obviously better, exceeding the national quality standard class III for groundwater only in some areas of the Guohe River Basin. However, without a large multiple of the excess, the deep groundwater is suitable as a source of drinking water.

There are three main reasons for the poor quality of shallow groundwater in the HRB: first, the background value of groundwater quality in this area has been high, since ancient times due to primary sedimentation, etc. Second, the flooding of the Yellow River has changed the normal relationship among recharge, flow-off, and draining, resulting in poor drainage of groundwater and the emergence of a large number of saline-alkali soils, which greatly delayed the natural desalination process of groundwater. Third, agricultural irrigation and domestic pollution have caused a certain degree of pollution to shallow groundwater due to high-intensity human activities in recent years.

We can see from the research results of the renewable capacity of the deep and shallow groundwater in the three systems that the Ancient Yellow River System groundwater system has the strongest renewable capacity, and at the same time, the possibility of deep groundwater being polluted is higher, especially in Huai' an and Suqian, where the shallow groundwater quality is poor. In such places, when developing and utilizing deep groundwater resources in this area, we should be more vigilant to prevent shallow groundwater migration from polluting deep groundwater. 


\section{Conclusions}

A broad-scale groundwater investigation was carried outalong 4 profiles, covering 14 cities in the HRB. A total of 390 samples were collected to characterize the degree of hydraulic interconnection between shallow and deep components of the groundwater flow systems that were intersected along these transects. Based on the analysis of the composition of ${ }^{18} \mathrm{O}$ and $\mathrm{D}$ isotopes in the collected water samples from various kinds of deep wells, we conclude that there is an obvious difference between the shallow and deep components of the flow systems that indicate that there is variable hydraulic interaction with depth. Three major deep groundwater systems can be identified: the Shayinghe River deep groundwater system, the Guohe River deep groundwater system, and the Ancient Yellow River deep groundwater system.

For the different deep groundwater systems identified above, the isotopic and hydrochemical characteristics of the shallow and deep layers of the three systems were further compared. The qualitative analysis shows that the deep and shallow groundwater connection of the ancient Yellow River system is the strongest and that of the Guohe River System is the weakest, indicating that the Ancient Yellow River System is more renewable with more mining space. The method of combining stable isotopes and water chemistry was used for quantitative calculation. It shows that in the short term, the renewable water volume of the deep groundwater systems in the Ancient Yellow River System, Shaying River System and Guohe River System accounts for 36\%, 22\% and $12 \%$ of the total, respectively, which is the same as the qualitative analysis results. It shows that it is feasible to comprehensively use isotope and hydrochemistry to analyze the renewable capacity of groundwater.

The water sample analysis results show that the quality of shallow groundwater in the HRB is generally poor, and the quality of deep groundwater is good, forcing people to shift the target of groundwater exploitation from shallow to deep. Therefore, in the development and utilization of deep groundwater resources, the renewable capacity of local deep groundwater should be taken into consideration. Especially in places such as Huai' an and Suqian, where the quality of shallow groundwater is poor, the strong renewable capacity of the local deep and shallow groundwater should be taken into consideration. Groundwater protection should be well conducted to prevent deep groundwater pollution when the deep groundwater in these places is extracted.

Acknowledgements We would like to thank the Huaihe River Commission of the Ministry of Water Resources P.R.C for help during sampling in the field. This research is financially supported by the National Key Research and Development Plan of China (2016YFC0402800).

Open Access This article is licensed under a Creative Commons Attribution 4.0 International License, which permits use, sharing, adaptation, distribution and reproduction in any medium or format, as long as you give appropriate credit to the original author(s) and the source, provide a link to the Creative Commons licence, and indicate if changes were made. The images or other third party material in this article are included in the article's Creative Commons licence, unless indicated otherwise in a credit line to the material. If material is not included in the article's Creative Commons licence and your intended use is not permitted by statutory regulation or exceeds the permitted use, you will need to obtain permission directly from the copyright holder. To view a copy of this licence, visit http://creativecommons .org/licenses/by/4.0/.

\section{References}

Alaya MB, Saidi S, Zemni T, Zargouni F (2014) Suitability assessment of deep groundwater for drinking and irrigation use in the Djeffara aquifers (Northern Gabes, south-eastern Tunisia). Environ Earth Sci 71(8):3387-3421. https://doi.org/10.1007/s12665-013-2729-9

Appelo CAJ, Postma D (2005) Geochemistry, groundwater and pollution. Balkema Rotterdam. https://doi.org/10.2136/vzj2005.1110br

Burgess WG, Hoque MA, Michael HA et al (2010) Vulnerability of deep groundwater in the Bengal Aquifer System to contamination by arsenic. Nat Geosci 3(2):83-87

Chatterjee R, Purohit RR (2009) Estimation of replenishable groundwater resources of India and their status of utilization. Curr Sci India 96(12):1581-1591

Cheng SP (2011) Study on Groundwater Pollution in Huaihe Plain of Henan Province. China University of Geosciences Press CO. LTD, Wuhan

Christen E, Khan S (2002) Technical constraints to deep groundwater pumping for conjunctive water management in the Coleambally Irrigation Area, Australia. J Viral Hepatitis 15(15):747-752

Foster SSD, Kemper KE (2002) Non-renewable groundwater resources, a guidebook on socially-sustainable management for water-policy makers. UNESCO, Paris

Foster SSD, Loucks DP (2006) Non-renewable groundwater resources, a guidebook on socially-sustainable management for water-policy makers. UNESCO, Paris

Gu WZ (2011) Isotope hydrology. Science Press, Beijing

Hasiniaina F, Zhou J, Guoyi L (2010) Regional assessment of groundwater vulnerability in Tamtsag Basin, Mongolia using drastic model. J Am Sci 6(11):65-78

Liu HB, Zhang YG et al (2005) Nitrate contamination of deep groundwater in rural plain areas of Beijing. Acta Pedol Sin 42(3):411-418

Hui ZG, Yu CZ et al (2000) Relationship between the formation of groundwater and the evolution of regional hydrologic cycle in North China Plain. Adv Water Sci 11(4):415-420

Ji CM, Wang ZX (1999) Sustainable development of groundwater resources. Geological Publishing House, Beijing

Jiao JJ, Wang XS, Nandy S (2005) Confined groundwater zone and slope instability in weathered igneous rocks in Hong Kong. Eng Geol 80(1):71-92

Kouassy KPS, Ndam NJR (2016) The catchment area of Kadey in East-Cameroon: assessment of arsenic contamination in deep groundwater resources. J Geol Geophys 5(4):1-10

Lee KS, Wenner DB, Lee I (1999) Using H- and O-isotopic data for estimating the relative contributions of rainy and dry season precipitation to groundwater: example from Cheju Island, Korea. J Hydrol 222(1-4):65-74 
Lloyd JW (1990) Groundwater resources development in the Eastern Sahara. J Hydrol 119(1):71-87

Maliva R, Missimer T (2012) Non-renewable groundwater resources, arid lands water evaluation and management. Springer, Berlin, Heidelberg

Mallamace F, Corsaro C, Chen SH et al (2013) Transport and dynamics in supercooled confined water. Liq Polymorph 152:203-262

Margat J, Saad KF (2010) Concepts for the utilization of non-renewable groundwater resources in regional development. Nat Resour Forum 7(4):377-383

Margat J, Frenken K, Faurès JM (2005) Key water resources statistics in AQUASTAT, FAO's global information system on water and agriculture. IWG-Env Int Work Session Water Stat Vienna 7(20-22):1-13

Michael HA, Voss CI (2008) Evaluation of the sustainability of deep groundwater as an arsenic-safe resource in the Bengal Basin. Proc Natl Acad Sci USA 105(25):8531-8536

Nandimandalam JR (2012) Evaluation of hydrogeochemical processes in the Pleistocene aquifers of Middle Ganga Plain, Uttar Pradesh. India Environ Earth Sci 65(4):1291-1308

Pedersen K, Bengtsson AF, Edlund JS, Eriksson LC (2014) Sulphatecontrolled diversity of subterranean microbial communities over depth in deep groundwater with opposing gradients of sulphate and methane. Geomicrobiol J 31(7):617-631
Shrestha RR, Shrestha MP, Upadhyay NP et al (2003) Groundwater arsenic contamination, its health impact and mitigation program in Nepal. J Environ Sci Health A Tox Hazard Subst Environ Eng 38(1):185-200

Stober I, Bucher K (1999) Deep groundwater in the crystalline basement of the Black Forest region. Appl Geochem 14(2):237-254

Yu GY (2014) Assessment of shallow groundwater vulnerability in Huaihe basin plant area based on improved DRASTIC method. Dissertation, Nanjing University

Yurtsever Y, Payne BR (1979) Application of environmental isotopes to groundwater investigations in Qatar. Proc Symp Isot Tech Groundwater Hydrol Vienna 2:465-490

Zhang GH, Chen ZY, Fei YH (2000) Relationship between the formation of groundwater and the evolution of regional hydrologic cycle in North China Plain. Adv Water Sci 11(4):415-420

Publisher's Note Springer Nature remains neutral with regard to jurisdictional claims in published maps and institutional affiliations. 